International Journal on Organic Electronics (IJOE) Vol.2, No.3/4, October 2013

\title{
FABRICATION AND CHARACTERIZATION OF CONDUCTING POLYMER COMPOSITE
}

\author{
Ritu Tomar ${ }^{1}$ and Dr. Chirag R Sharma ${ }^{2}$ \\ ${ }^{1}$ Department of Engineering Physics, \\ Sambhram Institute of Technology and \\ Research Scholar, Nitte Research and Education Academy, \\ Bangalore, India. \\ ${ }^{2}$ Department of Electronics, \\ Nitte Research and Education Academy, \\ Bangalore, India.
}

\begin{abstract}
The ion conducting polymer composite specimen has been prepared by using Polyvinyl-pyrrolidone $(P V P)$ and Potassium hydroxide $(\mathrm{KOH})$ using double distilled water as the solvent. The solution cast techniques was used to prepare the specimens. The main objective of the project is to study structural and mechanical properties of the polymer composite specimen. The conductivity and micro structure analysis has been carried out. The results revealed conductivity and hardness of the polymer composite increased with concentration of the $\mathrm{KOH}$ salt
\end{abstract}

\section{KEYWORDS}

Poly vinylpyrrolidone (PVP), Potassium hydroxide (KOH), Micro hardness, Conductivity.

\section{INTRODUCTION}

Poly vinylpyrrolidone (PVP), also commonly called polyvidone or povidone, is a polymer made from the monomer vinylpyrrolidone. It is flaky powder and absorbs water upto $40 \%$ of its own weight and is water soluble and also in polar solvents and has excellent wetting properties and readily forms films. This makes it good as a coating or an additive to coatings. PVP is used in a wide variety of applications. The main objective is to study the structural and mechanical properties of the polymer composite specimens prepared by PVP and $\mathrm{KOH}$. Micro hardness test was conducted using Vickers micro hardness tester to check the hardness of polymer composite specimen fabricated and the results showed that the polymer composite specimen as better hardness property.

The conductivity and dielectric constant tests of the polymer composite specimen were conducted using copper electrodes and multimeter. Result showed that conductivity of PVP polymer is improved by addition of $\mathrm{KOH}$ salt.

The micro structure analysis of given polymer composite specimen was conducted using metallurgical optical microscope, result shows the comparison between PVP polymer composite specimen and $\mathrm{PVP}+\mathrm{KOH}$ polymer composite specimen. 


\section{BEHAVIOR OF POLYMERS}

There are three types of behaviors in polymers , they are

\section{a] Thermal Behavior}

Thermoplastic and thermosetting polymers differ in that thermoplastic polymers actually melt and lose all semblance of crystallinity at high temperatures. After polymerisation the thermosetting plastics can lose its strength if they are subjected to higher temperature

The most critical effect of increased temperature is an increased rate of chemical reaction. The mechanical strength of the polymer drops rapidly at the same temperature where the polymer becomes susceptible to chemical reaction.

\section{b] Mechanical Behavior}

A polymer in molten state is amorphous in nature and has random chain orientation. By quenching structure of the molecules at higher temperatures can be preserved at lower temperature. The tension produces most of the initial deformation and improves the alignment of the molecules. As a result the stress-strain relationship is not like those of metals, because the molecules of elasticity are increased when the stress is applied directly against the polymer chain after the alignment has occurred.

\section{c] Electrical Behavior}

There is considerable use of plastics in electrical insulation. They can be made conductive and has some applications

Dielectric constant: the dielectric properties of polymers are sensitive to the polarization of the structure.

Conductivity: Although polymers are inherently insulators their compositions can be adjusted to permit some conductivity.

\section{OBJECTIVES OF THE STUDY}

\section{a. Fabrication of PVP : KOH polymer composite}

PVP polymer is mixed with $\mathrm{KOH}$ salt using solution casting method in magnetic stirrer and is allowed to solidify in open atmosphere.

\section{b. To evaluate the physical properties of polymer composite specimen}

The physical properties like conductivity, dielectric constant will be evaluated using multimeter and copper electrodes.

\section{c.To evaluate the mechanical properties of polymer composite specimen}

The mechanical properties such as micro hardness will be experimentally determined 


\section{d. Micro-structural study of polymer composite specimen}

Micro-structural analysis of polymer composite specimen is conducted using metallurgical optical microscope.

\section{SPECIMEN PREPARATION}

The surface are cleaned using acetone and cotton and the clean surface is sprayed with silicon spray.

After that a sample is prepared using PVP of weight $10 \mathrm{~g}$ and potassium hydroxide of weight $3 \mathrm{~g}$ using double distilled water.

The mixture of $\mathrm{PVP}+\mathrm{KOH}+$ double distilled water is poured into a conical flask.

The mixture of $\mathrm{PVP}+\mathrm{KOH}+$ double distilled water is stirred in a magnetic stirrer

After stirring for some time the sample is poured into polypropelene mould with the help of funnel.

The sample is then dried in room temperature.

The polymer composite specimen are tested for is structural behaviour and mechanical properties.

\section{MICROSTRUCTURE ANALYSIS}

The following Fig 1 shows the microstructure analysis of $\mathrm{PVP}+\mathrm{KOH}$ specimen.

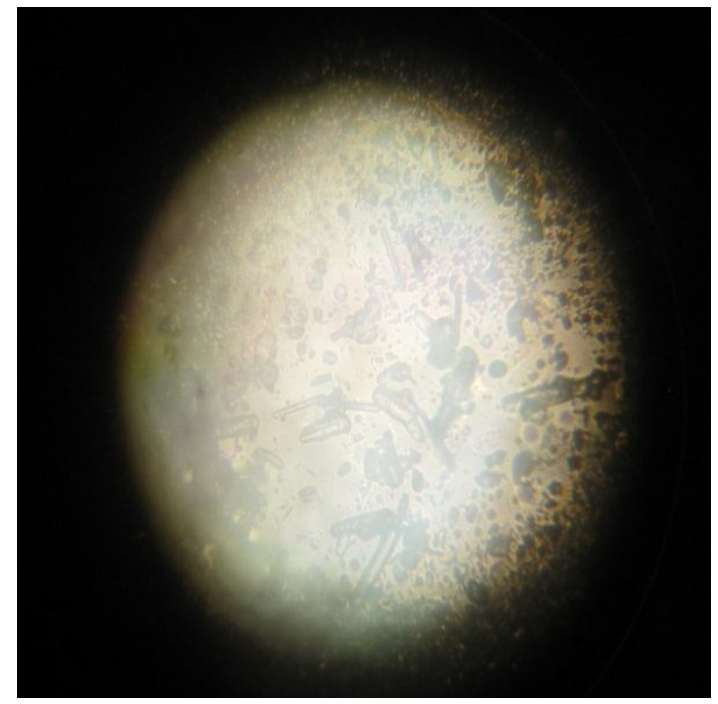

Figure1 Micro structure of $\mathrm{PVP}+\mathrm{KOH}$ polymer composite specimen

Metallurgical microscope is used for the analysis of $\mathrm{PVP}+\mathrm{KOH}$ polymer composite specimen. Magnification factor of above polymer composite specimen is 2000X. The microsturcture analysis indicates good distribution of $\mathrm{KOH}$ in PVP 


\section{ELECTRICAL CONDUCTIVITY}

The ionic conductivity of the poly vinyl pyrrolidone based polymer electrolyte film was carried out using $\mathrm{CH}$ instrument workstation. To measure ionic conductivity (s) we have used steel electrodes and calculated ionic conductivity values using formula

$\sigma=\left(G^{*} \mathrm{t}\right) / \mathrm{A}$

Where,

$\sigma$ - Conductivity(Siemens/metre), t-Thickness, R - Bulk resistance A - Area

where, $s$ is ionic conductivity, $\mathrm{G}$ is conductance $(1 / \mathrm{Rb}, \mathrm{Rb}$ is bulk resistance where the Nyquist plot intercepts with the real axis), $t$ is thickness of sample and $\mathrm{A}$ is the area of given sample. The room temperature ionic conductivity of polymer electrolytes shown in Fig. 2 and values are listed in Table 1. As observed in Fig. 2, the ionic conductivity (s) increases with the increase in $\mathrm{KOH}$ concentration and reaches maxima at $35 \mathrm{wt} \% \mathrm{KOH}\left(\mathrm{s}=4 \times 10^{-4} \mathrm{~S} / \mathrm{cm}\right)$

Table 1 Room temperature ionic conductivity of the PVP:KOH polymer electrolyte system

\begin{tabular}{|c|c|c|}
\hline S1 no & $\begin{array}{c}\text { PVP:KOH } \\
(\mathrm{wt} \%)\end{array}$ & $\begin{array}{c}\text { Conductivity } \\
(\mathrm{S} / \mathrm{cm})\end{array}$ \\
\hline 1 & $80: 20$ & $1.4 \times 10^{-6}$ \\
\hline 2 & $75: 25$ & $5 \times 10^{-5}$ \\
\hline 3 & $70: 30$ & $1.8 \times 10^{-4}$ \\
\hline 4 & $65: 35$ & $4 \times 10^{-4}$ \\
\hline 5 & $60: 40$ & $3.4 \times 10^{-4}$ \\
\hline
\end{tabular}


International Journal on Organic Electronics (IJOE) Vol.2, No.3/4, October 2013

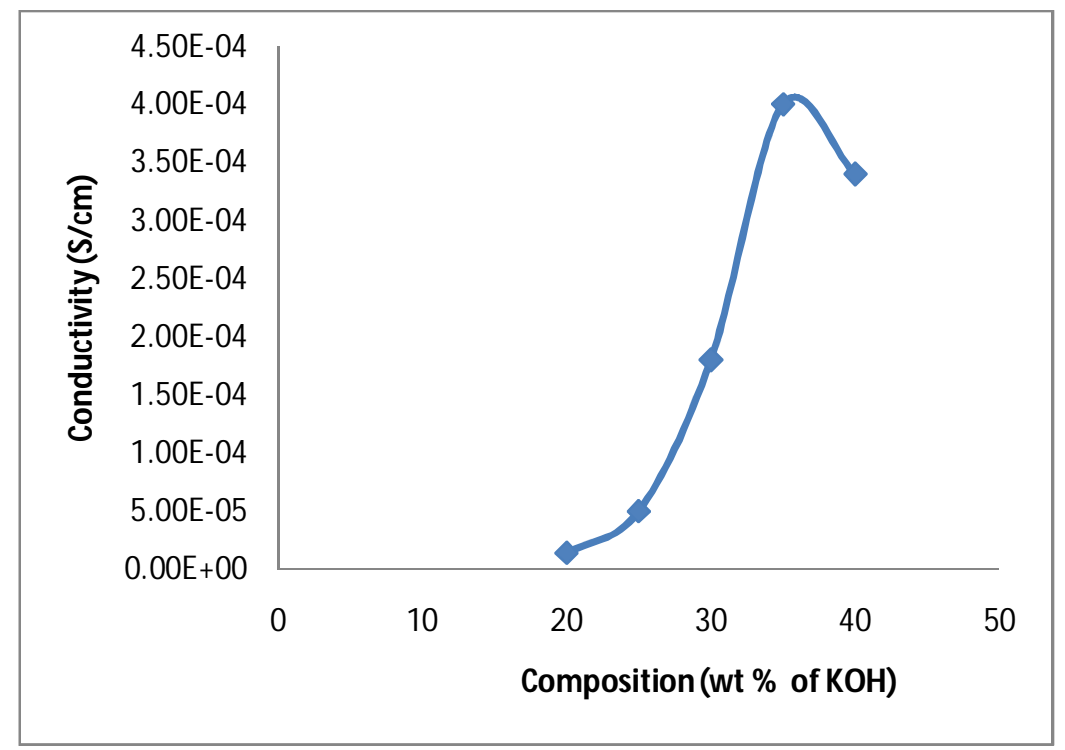

Fig 2. Effect of $\mathrm{KOH}$ content on the conductivity of the polymer electrolyte (PVP: KOH) measured at room temperature.

\section{MICRO HARDNESS TEST}

The micro hardness tests are used to determine the resistance of a material to deformation. This tests can be performed on a macroscopic or microscopic scale.

The metals indentation hardness correlates linearly with tensile strength. This important relation permits economically important non destructive testing of bulk metal deliveries with lightweight, even portable equipment, such as automatic Vickers micro hardness testers as shown in Fig 3.

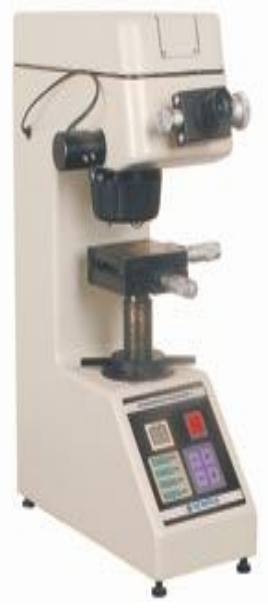

Figure 3 Vickers micro hardness tester

The specimen is placed on an anvil which has a screw threaded base and the test is conducted 
International Journal on Organic Electronics (IJOE) Vol.2, No.3/4, October 2013

The controlled test force the specimen is pressed with the indenter with a dwell time of 10 to 15 seconds.

The indenter is removed forming an indent in the sample that appears square shaped.

The size of the indent is determined optically by measuring the two diagonals of the square indent.

The Vickers hardness number is obtained by the test force divided by the surface area of the indent. The average of the two diagonals is used in the formula to calculate the Vickers hardness. The applying and removing the load is controlled automatically.

The Fig4 below shows the specimen placed on the anvil that has a screw treaded base.

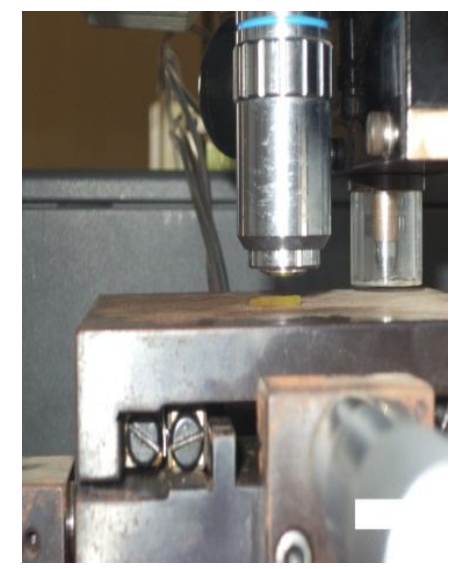

Figure 4 Specimen placed on the Vickers micro hardness tester

The Vickers micro hardness $\mathrm{H} \mathrm{V}$ is calculated by using formula

$\mathrm{HV}=1.854 \mathrm{~F} / \mathrm{d}^{2}$

Where $\mathrm{F}$ is load applied in kgf,

$\mathrm{d}$ is mean of the two diagonals, $\mathrm{d} 1$ and $\mathrm{d} 2$ in $\mathrm{mm}$

$\mathrm{HV}$ is Vickers hardness,

Dwell time $=10$ seconds

\section{Table 2 Hardness value of polymer composite}

\begin{tabular}{|c|c|c|c|c|c|c|c|}
\hline $\begin{array}{l}\text { Sl } \\
\text { No. }\end{array}$ & $\begin{array}{c}\text { Load } \\
\mathbf{G r a m s}\end{array}$ & $\begin{array}{c}\text { Load } \\
\mathbf{k g f}\end{array}$ & $\begin{array}{c}\mathbf{d}_{1} \\
(\mathbf{m m})\end{array}$ & $\begin{array}{c}\mathbf{d}_{\mathbf{2}} \\
(\mathbf{m m})\end{array}$ & $\begin{array}{c}\mathbf{d =} \frac{\mathbf{d}_{1}+\mathbf{d}_{2}}{\mathbf{2}} \\
(\mathbf{m m})\end{array}$ & $\begin{array}{l}\text { Scaling Factor } \\
\mathbf{D = d ^ { * }}\end{array}$ & $\begin{array}{c}\mathbf{H} \mathbf{0 . 1 1 5 4} \\
\frac{\mathbf{1 . 8 5 4 F}}{\mathbf{D}^{2}} \\
\left(\mathbf{N} / \mathbf{m m}^{\mathbf{2}}\right)\end{array}$ \\
\hline 1 & 100 & $\begin{array}{c}0.98 \\
1\end{array}$ & 3.2 & 3.3 & 3.25 & 0.37505 & 13.28 \\
\hline 2 & 200 & $\begin{array}{c}1.96 \\
2\end{array}$ & 3.0 & 3.12 & 3.06 & 0.35312 & 29.69 \\
\hline
\end{tabular}


International Journal on Organic Electronics (IJOE) Vol.2, No.3/4, October 2013

\begin{tabular}{|c|c|c|c|c|c|c|c|}
\hline 3 & 300 & $\begin{array}{c}2.94 \\
3\end{array}$ & 2.62 & 3.16 & 2.89 & 0.33352 & 49.22 \\
\hline 4 & 500 & $\begin{array}{c}4.90 \\
5\end{array}$ & 2.22 & 2.24 & 2.23 & 0.25734 & 137.6 \\
\hline
\end{tabular}

For the load of $0.98,1.962 .943 \mathrm{and} 4.905 \mathrm{kgf}$, the hardness number was in the range of 13.28 to 137.6 At a $4.905 \mathrm{kgf}$ load, however, the hardness number suddenly increased to 137.6 as shown in Table2.

This indicated that the critical indentation load was $4.905 \mathrm{kgf}$. Moreover, the hardness of the specimens used in this study increases with the increasing test load, while others has reported the tendency of hardness of materials decreases with the increasing test load.

\section{Conclusions}

The conductivity of polymer composite specimen shows enhancement by $\mathrm{KOH}$ doping and highest conductivity was obtained at $35 \mathrm{wt} \% \mathrm{KOH}$ concentration with conductivity value of $2.78 \times 10^{-4} \mathrm{~S} / \mathrm{Cm}$. The micro hardness test of polymer composite specimen at $35 \mathrm{wt} \% \mathrm{KOH}$ concentration showing maximum conductivity has been carried out. For load of 0.98, 1.96 $2.943 \mathrm{and} 4.905 \mathrm{kgf}$, the hardness number was in the range of 13.28 to 137.6 . At a $4.905 \mathrm{kgf}$ load, however, the hardness number suddenly increased to 137.6. This indicated that the critical indentation load was4.905kgf. Metallurgical microscope was used for the micro-structural analysis of polymer composite specimen .The micro-structural analysis of $\mathrm{PVP}+\mathrm{KOH}$ polymer composite revels that $\mathrm{KOH}$ is evenly distributed throughout the specimen.

\section{REFERENCES}

[1] Igor S, Medeiros, Mauricio N. Gomes (2007)"Diametrial tensile strength and Vickers hardness of a composite after storage in different solutions" Journal of uralscience, Vol . 49 No. 1,pp 61 -66.

[2] T. Agarwal1, K. A. Gupta2, S. Alam3, M. G. H. Zaidi1 (2012) "Fabrication and Characterization of Iron Oxide Filled Polyvinyl Pyrrolidone Nanocomposites" International Journal of Composite Materials, Vol 2, No. 3, pp7-21.

[3] S K Tripathi, Ashish gupta and Manju kumara (2012). "Studies on electrical conductivity and dielectric behaviour of PVdF-HFP-PMMA-NaI polymer blend electrolyte" Vol. 35, No. 6, pp. 969-975.

[4] SRajendran, Ravi shanker Babu and M.Uusha Rani (2011).’Effect of complexing salt on conductivity of PVC/PEO polymer blend electrolytes". Bull. Mater. Sci@ Indian Academy of Sciences., Vol. 34, No. 7, pp. 1525-1530.

[5] Farzana Hussain,Mehdi Hojjati, Masami Okamoto, Russell e. Gorga(2006). "Polymer-matrix Nanocomposites, Processing,Manufacturing, and Application: An Overview”. Journal of Composite Materials, Vol. 40, No. 17.

[6] Tavman, V. Çeçe,I. Özdemir, A. Turgut, I. Krupa, M. Omastova b, I.Novak b.(2009). “ Preparation and characterization of highly electrically and thermally conductive polymeric nanocomposites".Archives of Materials science and Engineering, Vol. 40, No. 2, pp. 84-88. 


\section{Authors}

Short Biography

Mrs Ritu Tomar is working as Faculty of Engineering Physics in Sambhram Institute of Technology and Research Scholar at Nitte Research and Education Academy, Bangalore. She has published research paper in national and international Journals and Conferences

Dr Chirag R Sharma had obtained Ph.D and MS degree form University of Utah, USA and Presently working as Professor of Electronics at Nitte Research and Education Academy, Bangalore. Several research papers has been published in national and international Journals and Conferences. He is presently guiding 5 research scholars.
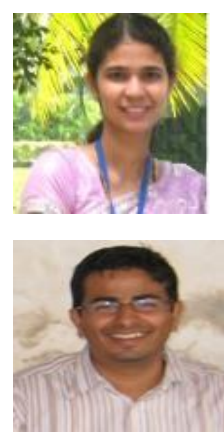